\title{
EMERGENCY TRANSPORTATION IN THE EVENT OF ACUTE SPINAL CORD LESION
}

\author{
By H. J. Hachen, M.D. \\ Centre de Paraplegiques, Hôpital Cantonal (Beau-Séjour), Genève, Switzerland
}

DISTRICT hospitals are often inadequately equipped and understaffed to deal efficiently with acute spinal injury cases. All too often patients develop pressure sores, respiratory insufficiency and serious urinary infections during the first few days after hospitalisation. Early complications can be prevented if all acite cases are immediately transferred to a specialised SCI Centre where first-class intensive care and appropriate treatment are immediately available.

We all know that rapid and precise assessment of the level and type of lesion is of paramount importance if the patient is to benefit from optimal therapy and to have a chance for possible functional improvement. Data received at the emergency desk is often fragmentary and insufficient. We therefore make it a rule that all victims with acute spinal injury should be considered and treated as having potential involvement of the cord.

Emergency transport should be both smooth and rapid. However, one must keep in mind that the quickest is not necessarily the best. In our mountainous regions, evacuation of the injured by ambulance is often impractical and timeconsuming. During week-ends, heavy traffic on main highways is likely to block easy access to the scene of the accident. This creates distressing situations both for the patient and the rescue-squad. On several occasions we have registered delays of up to 4 and 5 hours. In the presence of life-threatening lesions the situation may rapidly become dramatic (Robertson \& Tonge, I968).

These various considerations clearly stress the need for an efficient, nationwide rescue system. Entirely new standards have now been adopted in accordance with data compiled in other countries such as Germany, France and the United States, both during peace and war (Pilisbury, 1957; Engelmann, I962; Kliesch, I962; Salvacnac, I963; Ahnfeld, 1969).

Since 1965 we strongly insisted that all SCI patients should immediately be sent to one of thie country's paraplegic centres. Swiss Air Rescue (SRC) has been extremely helpful in organising the patient's initial transfer under optimal conditions. 'Acute spinal injury' is classified as top-urgent and always given priority assistance (von Ballmoos, I97I). Since I965, SRC, still a private organisation, is officially affiliated to the Swiss Red Cross. Aircraft carrying the sign of RSC may land and take off without restriction on all civilian and most military airports in Europe, Northern Africa and the Middle East. In many of these regions, adequate facilities for proper care of acute paraplegics are missing. This largely justifies the expenses involved in long-distance rescue flights.

The SRC squadron comprises of 25 helicopters of the type Bell-47, Bell-206. Jet Ranger, Alouette 3 I 5 Lama, Alouette III and Sikorsky S-58 T. These aircraft are all especially equipped with up-to-date first-aid material. On the regular check-list of over 300 items, figure a VISICARD-8 ECG-monitoring unit, a DEFI-CARD defibrillator, an AMBU respirator, a large display of surgical. 
instruments and suture material, a laryngoscope for emergency intubation, blood, plasma and saline for i.v.-drip and 35 carefully selected drugs to prevent and treat cardiovascular and respiratory disorders. All first-aid equipment is continuously improved according to the newest standards of medical technology.

In order to guarantee rapid on-the-spot availability the helicopters are permanently stationed at I3 carefully selected airports throughout the country. Alarm is given by dialing the nation-wide emergency code or 8 I4 I4 I4. SRC rescues about a thousand victims a year-about 25 per cent. during the months of July and August. The rescue programme is continuously monitored by radio shortwaves from headquarters in Zürich. Thus we are constantly informed about the helicopters exact location and flight-plan and our patient's condition on board. At the intensive care station all necessary steps can be taken well in advance and surgical measures applied immediately upon the patient's arrival.

At SRC both pilots and rescue workers are well acquainted with medical and surgical first-aid care. 'In order to be entitled to wear the official Red Cross badge they must have accomplished the regular training courses and attended the obligatory practical stages in several intensive care units of our state hospitals. There they are given specific guide-lines allowing them to better evaluate a patient's vital body functions at the scene of the accident.

For practical reasons we distinguish between first and second grade emergency. First grade rescue implies immediate airlift by helicopter from the site of the accident to our spinal care unit. Second grade applies to transport from smaller district hospitals or other countries where the patient has already had initial medical care. Since large distances are involved, we prefer to use aircraft with pressurised cabins, such as Cessna $4 \mathrm{I} 4$ and $42 \mathrm{I}$ and more recently the rapid Lear Jet 24D (Hagelstein \& Molte, I963).

Initial measures of resuscitation, such as intravenous administration of blood, plasma or saline, besides respiratory assistance and oxygen therapy should be systematically applied before allowing take-off. External haemorrhage must likewise be under control (Buergi, I963; Hartmann, I965; Goegler, I968; Orbach, I97I). During flight, patients in a critical state are permanently connected to an ECG-monitoring unit. Tetraplegics are never to be carried by air unless they are accompanied by an experienced anaesthetist. In the event of sudden respiratory insufficiency, equipment for tracheal intubation should be immediately available (Pons, I962).

Two types of stretchers have proved to be particularly helpful for patients with spinal injury-the Ferno-Washington Scoop-Stretcher and the 'multiplelamella' stretcher. Both models totally eliminate rolling and sliding and remove the possibility of aggravation of the original injury which is always likely to occur during a lot of handling involving several transfers. The scoop-stretcher's halves are adjustable in length to accommodate any size patient and can be easily joined and separated by means of a bipolar automatic latch-hinge. For flights over shorter distances the Laerdal Vacuum Mattress has also proved to be very helpful and convenient. It is filled with small expanded plastic balls and forms a firm mold around the patient.

A critical review of all acute cases, which were transferred to our department since the new rescue plan has been put into practice, reveals results that speak for themselves; no more patients died during the transport; the average time 
required for the rescue operation by air is now around 50 minutes as compared to $4 \frac{1}{2}$ hours under the former conventional system. Due to comprehensive medical care before and during the flight, the patient's state upon arrival in our hospital has usually already much improved and signs of cardiovascular shock and respiratory insufficiency are exceptional (Weil \& Shubin, 1967; Taubenhaus, 1972). The current concepts of management for spinal cord injury make the best possible use of already existing facilties and modern medical technology. Better information of the public (Hanlon, I973), improvements in the interstate communicationnetwork (Strange, I973) and a perfectly coordinated ground-air ambulance service have made the SRC rescue and trauma care programme one of the most efficient in the world.

In conclusion, chances for survival and adequate treatment of patients with acute spinal injury depend on a well-organised alarm system, optimal measures of cardio-respiratory resuscitation at the site of the accident and smooth and rapid transfer by helicopter to a specialised paraplegic centre.

\section{REFERENCES}

AHNEFELD, F. W. (1969). Der Einsatz von Hubschraubern bei der Versorgung von Notfallpatienten. Wehrmed. Mschr. 13, 329.

BuERGI, H. (1963). Medizinische Forderungen an den Transport von Notfallpatienten. Schweiz. Aerztezeitung, 44, 219.

EngelmanN, K. G. (1962). Der Hubschrauber als Rettungsmittel im ärztlichen Dienst. Müncher Med. Wschr. 104, 1985.

GoEgleR, E. (I968). Organisation und Ausrüstung für die ärztliche Erstversorgung am Unfallort. Kapsel, 23, 833 .

Hagelstein, J. \& Nolte, H. (I963). Medizinische Probleme beim Lufttransport Kranker und Verletzter. Anaesthetist, I2, 27 I.

Hanlon, J. J. (I973). Emergency medical services. Health Services Reports, 88, 205.

HartmanN, K. (1965). Aerztliche Hilfe und Versorgung am Unfallort. Med. Welt, 22, I 189.

KliesCH, H. (1962). Der Hubschrauber als Krankentransportmittel. Wehrmed. Mitteilungen, $\mathbf{I}, 5$.

ORBACH, H. (I97I). Erstversorgung am Unfallort. Stuttgart: Georg Thieme.

PilisBURY, D. (1957). Experiences in air evacuation of severely burned patients. Military Medicine, 120, 202.

Pons, R. (1962). Les évacuations par voei aérienne des insuffisants respiratoires aigus. Thèse Nr. I73. Faculté de Médecine de Lyon.

Robertson, J. S. \& Tonge, J. I. (I978). Duration of survival in traffic accident fatalities. Med. F. of Australia, 2, 57 I.

Salvagnac (1963). Les évacuations aéro-médicales. Forces aériennes franc. 2, 22 I.

St. Clair Strange, F. G. (I973). An area accident service. R.S.H. I, 3I.

Taubenhaus, L. J. (1972). What to do until the ambulance comes. New York State Med. F. 72, 500 .

Von Ballmoos, H. (I97I). Die Bedeutung des Lufttransports in der schweizerischen Bergrettung; Inaugural-Dissertation; Med. Fakultät Zürich; Institut für Anästhesiologie.

Weil, M. H. \& Shubin, H. (1967). Diagnosis and treatment of shock. Baltimore: Williams and Wilkins.

WING, J. E. (I956). Helicopter mobile medical companies in the fleet marine forces. U.S. Armed Forces Med. F. 7, I802. 


\section{Discussion}

The Chairman speaking on behalf of the meeting congratulated Dr. Hachen on his appointment in Geneva as successor to Dr. Alain Rossier and wished him well in his new appointment.

DR. A. G. HARDY (G.B.). The moral of the story is that if you must have an accident have it in Switzerland. Do you know how much it costs to have a system like that ?

DR. F. W. MEINECKE (Germany). I have two comments with regard to the European system. Firstly, if the patient is brought immediately from the accident to a spinal unit, one must be aware that there are not enough beds available-probably, in Germany there is needed 1000 more beds in spinal units. The other point is that to go over to another country to pick up a patient is a very good idea. In our country, most of the rescue work is done by the Air Force. However, the Air Force is not allowed to go over Switzerland but has to go over to Austria.

DR. J. B. Cook (G.B.). I feel they do things much better than we do. Rather reluctantly I sent for a patient by helicopter from Blackburn the other day and the chap who set off by car at the same time arrived an hour and a half earlier!

DR. J. J. WALSH (G.B.). I want to congratulate Dr. Hachen on an excellent paper. I think we tend to underestimate the value of this very initial treatment of these patients. For many years, as most of you know, Ireland has done the same thing but probably slightly cheaper than in Switzerland. Many many years ago a man called Armstrong, from one of the southern American states, published a paper where he analysed his paraplegics. I think he found Io percent. of them developed their paraplegia between the accident and getting into hospital. A few of these might have been due to haemorrhages but I think the majority were due to mishandling. Since I96I, I have been most impressed with the very high incidence of incomplete lesions in the Irish Unit, where they send out helicopters as you do. I do think we can't emphasise too much the value of initial treatment. We have been talking today about operations; I think the correct handling in the first few hours is at least as important as any operation you can produce.

Chairman (Dr. D. J. E. Cheshire). May I emphasise that from the chair. I am convinced from my own experience, exactly as is Dr. Walsh, that the better the handling system the higher the incidence of incomplete lesions arriving at the acute unit.

Dr. Hachen (Switzerland). On the questions of the costs of these flights, they are not very costly because the country covers only 16,000 square miles. We are a small country, and the average flight, as I said, only takes about 45-50 minutes. The average rescue flight costs about 250 dollars at the present time, which is not excessive. It is usually taken in charge by various insurance companies.

DR. A. G. HARDY. What is the average time from the accident to the time you are called? I imagine if someone is at the top of a mountain and has a fall it is going to take a day or so before you are notified.

DR. HACHEN. It is exceptional that a patient has an accident unseen or unheard of. Usually, they give us notice half an hour following accidents.

Sir Ludwig Guttmann (G.B.) When we set up our helicopter service at Stoke Mandeville in I958, this was done with special reference to cervical cases. For these patients it is an absolutely life-saving procedure. I must say our Air Force has done excellent work. Here, in particular, I should like to compliment Mr. Griffiths, who, when serving in the R.A.F., would ring me up, for instance from Cyprus to say-'Can I send you a case immediately ?'. Naturally the answer was 'Yes'. The transport by air was perfect and the patient arrived within 4 hours. This service has been taken over for some years by the Health Service and it has certainly improved the number of incomplete lesions and at least has improved the possibility to give immediate and proper treatment. The second point is that it is a fact that most of the patients are transported from the place of accident firstly to the nearest hospital. For many years now we have convinced our orthopaedic or accident colleagues to get in touch with us immediately, and if the patient has some additional injury and cannot be transported the surgeon will ask 
the spinal specialist about the initial management in the meantine. This has undoubtedly increased the number of patients who come to us with a sterile bladder, because we tell the surgeon or the medical staff 'Don't touch the bladder and don't put a catheter in, just leave the bladder alone for 24 hours and send the patient as soon as he is transportable'.

DR. P. Dollfus (France). I think here Sir Ludwig has put his finger on the whole problem. Unfortunately what we are seeing nowadays in France is that general, orthopaedic or traumatological surgeons immediately operate, plate, wire or screw, and the paraplegist is very often asked too late to take the patient. I think that this is a very grave problem and I think it's the ego of the surgeons that in France have pushed the neurosurgeons aside. The traumatological surgeons say: 'We must have the patients immediately, we must treat them immediately.' Well this is a little bit like the Far West -'I will shoot first and ask questions after'. Then they send the patients to me screwed, plated, and in a terrible state. It's all very well to have helicopter service provided it's used to transport patients before they have been screwed!

Professor A. Rossier (U.S.A.). I wish to make a comment on this excellent paper which warmed my heart. We started almost at the same time as Dr. Hachen on this system of transportation. There is one thing which all of us should know. That is that the Swiss system is absolutely free in choosing a hospital. In fact, if the people wanted to transport the man to another hospital they are absolutely free to do so. What is important is that they understand that the best care in transport is by helicopter. I also think it is important that other hospitals are aware of the helicopter and are aware of the fact that there are Spinal Injuries Centres.

Dr. J. J. WALSH. May I ask our friend Alain and also Dr. Hachen how they achieved a free service like this. It is important to many other countries. Was it due to the Ministry of Health, to a politician or what?

Professor A. Rossier. As far as I know-and I don't think it has changed, they are still working on the same basis-that it is absolutely private but they get money partly from the Federate State and partly money from many private sources.

DR. HACHEN. You can become a member of the Swiss Air Rescue Society-the fee is $£ .3$ a year yourself, or you can have the whole family join for $£$ io. When you justify the need for helicopter transport in a case such as spinal cord injury, or cerebral trauma due to a car accident, or in a case of open fracture suffered while you are in Algeria or Tunisia, the Society fetch you wherever you are-Europe, North Africa or the Middle East-free of charge. I think this has created a lot of interest in the community.

DR. J. J. WALSH. I think I should say in all fairness to Britain that the transportation by helicopter is free as far as the patient is concerned, but we have difficulty with the money taken from the 'right pocket and the left pocket'. The Ministry of Health with the Air Force arrange the helicopter but the Region or Local Authority pay $£ 60$ an hour for one helicopter. May I ask, is there anyone responsible in Switzerland, such as the local authority, that pays for a patient from one canton to another canton?

Reply-No.

MR. W. S. KeRR (G.B.). May I say there is a slight difference in Scotland. Our air ambulances do not come under the local authorities-they are centralised under the National Health Service. If a surgeon in Fort William or Inverness feels that air transport is necessary, all he has to do is persuade the Regional Ambulance Controller of the National Health Service. The local authority is not involved.

E. R. GRIfFiths (Australia). I should just like to add to Dr. Hachen's wonderful paper, those who have not used transportation of spinal injuries by air should remember that any high paraplegic, especially tetraplegics, have respiratory difficulties and you must make sure of your patient before you take him up. If your aircraft is not pressurised down to 2000 or 4000 feet, you are in real trouble. So, you must have a properly equipped aircraft and make sure that the aircraft can be pressurised.

ChaIRMAN. I think you will agree with me that we have had a most varied and most interesting afternoon's programme of the highest quality and instruction. I would like on your behalf to thank the contributors. 